\title{
Evaluation of evapotranspiration and deep percolation under mulched drip irrigation in an oasis
} of Tarim basin, China

\author{
Xianwen Li ${ }^{1,2}$, Menggui Jin ${ }^{2}$, Nianqing Zhou ${ }^{1}$, Jinou Huang ${ }^{2}$, Simin Jiang ${ }^{1}$, Habiyakare Telesphore ${ }^{1}$ \\ ${ }^{1}$ Department of Hydraulic Engineering, Tongji University, Shanghai 200092, China; \\ ${ }^{2}$ State Key Laboratory of Biogeology and Environmental Geology \& School of Environmental Studies, \\ China University of Geosciences, Wuhan 430074, China
}

Corresponding author:

Menggui Jin, State Key Laboratory of Biogeology and Environmental Geology \& School of Environmental Studies, China University of Geosciences, Wuhan 430074, China,

Tel.: 86-27-67883461; fax: 86-27-87436235; e-mail: mgjin@cug.edu.cn

\begin{abstract}
Mulched drip irrigation for cotton field is an effective measure for the utilization of saline water, and the regulation of soil water and salt. However, the reasonable methods for quantifying actual evapotranspiration (ET) and deep percolation of recharge to groundwater are still not very well understood, which restricts the accurate regulation of soil water and salt for cotton growth in oasis. In this paper, a set of experiments of mulched drip irrigation with brackish water were conducted in a typical arid region of Tarim basin in southern Xinjiang, China. The irrigation events were recorded, and ET and fluctuations of groundwater table were carefully measured for two consecutive irrigation periods of flowering and bolling stages. A group of upscaling conversion methods were used to quantify the ET, in which canopy structure was considered to estimate the transpiration from leaf scale to a unit of field scale. The groundwater table had a significant response to the irrigation events, thus
\end{abstract}


the deep percolation was estimated using water-table fluctuation method (WTF). Results showed that during the two irrigation events of flowering and bolling stages, the total ET was $31.1 \mathrm{~mm}$ with the soil surface evaporation of only $0.4 \mathrm{~mm}$. The total percolation of recharge to groundwater was $48.2 \mathrm{~mm}$ which contributed to the groundwater run-off of $22.1 \mathrm{~mm}$. Transpiration of $30.7 \mathrm{~mm}$ accounted for $98.6 \%$ of the total ET of $31.1 \mathrm{~mm}$ and $34.3 \%$ of the irrigation water of $90.6 \mathrm{~mm}$. Compared with transpiration, the deep percolation accounted for $53.2 \%$ of irrigation water, indicating a serious excessive irrigation that recharged to groundwater. Soil salt budget showed that the salt leached into groundwater was 1.56 times of the input from brackish irrigation water and fertilization during the two irrigation periods. Even for the irrigation practice with brackish water, the accumulated salt of soil profile could also be leached out under large amount of irrigation water (e.g. $90.6 \mathrm{~mm}$ for the two irrigation periods, 10 days). However, the waste of enormous water which for instance occupied $53.2 \%$ of the irrigation water in this study was not conducive to the sustainable utilization of water resources in the arid oasis. Furthermore, the methods introduced in this paper for ET and deep percolation calculation of cotton filed could be used to quantify the oasis hydrologic cycle of micro-irrigation, to gain a better understanding of the ecological process.

Key words: Agriculture, Salinization, SRS-2000 equipment, Groundwater, Xinjiang

\section{Introduction}

Water shortage and soil salinization are the two main problems for sustainable development of agriculture in arid areas (Chen et al., 2010; Danierhan et al., 2013; Valipour, 2014a, 2014b, 2015a). Taking Xinjiang in northwest China as a typical region, more than 50\% of rivers are developed for irrigated agriculture, and $70 \%$ of which are inland (Li, 2003). Excessive use of water resources in 
continental river basin results in drying up of the downstream rivers and lakes, and expanding of desertification $(\mathrm{Li}, 2003)$. In recent years, drip irrigation as a practice of saving water and increasing water use efficiency is widely promoted in arid areas (e.g., Assouline et al., 2006; Sezen et al., 2006; Vazquez et al., 2006; Marouelli and Silva 2007; Bhattarai et al., 2008; Li et al., 2012; Valipour, 2012; Panigrahi et al., 2013; Selim et al., 2013 and others). With the features of drip irrigation and surface film, mulched drip irrigation can effectively reduce evaporation and deep percolation, and has been applied increasingly in Xinjiang since the early 1990s (Liu et al., 2012). Compared with the world average of $1.5 \%$, however, only $0.5 \%$ of the total cultivated land is the drip-irrigated area in China (Niu et al., 2010). On the other hand, the pressurized systems should also be improved economically to increase water use efficiency (WUE) (Valipour, 2012).

Irrigation with water that has elevated salinity provides another possibility to meet the increasing water demands (Oron et al., 2002; Letey et al., 2011). Shallow brackish water with total dissolved solids (TDS) of 2 3 g/L distributes widely throughout north and northwest China, where freshwater is in shortage. The quantity of brackish water used for agriculture is about 13 billion $\mathrm{m}^{3}$ in these regions (Yang and Cheng, 2004). Rational usie of brackish water is one of the most important ways for water-saving agriculture (Wang et al., 2002). Mulched drip irrigation with brackish water has then gradually become a new type of field management practices (Wang, 2013; Wang et al., 2014). During irrigating, solute salt in irrigation water accumulates in soils and gradually stores at the root zone by root water uptake. Besides, soil evaporation mainly occurs between mulches, and salts usually accumulate along the wetting fronts and the bare soil belts, which always lead to soil salinization (Mirjat et al., 2014) and affects the sustainable utilization of brackish water (Araguiés et al., 2015). With the years of increasing mulched drip irrigation with brackish water, the depth of $30 \sim 60 \mathrm{~cm}$ is the main 
part of salt accumulation (Wang, 2013). Another factor of secondary salinization is the upward saline groundwater by capillary rise, resulting from shallow water table and strong soil evaporation in arid region (Hamed, 2008).

All the above requires the adoption of comprehensive water-saving measures, which can increase irrigation efficiency and reduce invalid evaporation. Meanwhile, the amount of the salt leached into soils and the deep percolation reduce through minimizing the amount of irrigation water, which could also decrease water table. However, reviews of previous studies as shown above, indicate that it is extremely difficult to accurately estimate the actual evapotranspiration (ET) and deep percolation of recharge to groundwater, which is crucial for the scientific strategies of soil water-and-salt management in oasis. In this paper, a set of experiments of mulched drip irrigation with brackish water were carried out at a typical oasis of Tarim basin, China. Group methods of upscale conversion were used to quantify the ET especially for the transpiration from leaf scale to a unit area of filed scale. Meanwhile, the water-table fluctuation method (WTF) was used to estimate deep percolation for a certain irrigation period. Based on these, soil water and salt budgets were also carefully discussed to reveal the mechanism of soil water and salt storage in soil profile under mulched drip irrigation. The paper provides a case study of calculating ET and deep percolation for micro irrigation, which can be potentially applied in other arid inland areas (e.g., central Asia) with similar water shortage situations.

\section{Details of the experimental site}

The experimental site is located in an alluvial plain of the Kongqi River with the east longitude of $86^{\circ} 10^{\prime}$ and north latitude of $35^{\circ} 41^{\prime}$, and belongs to the Water Resources Research Institute, an embranchment of Tarim River Basin Management Bureau in the arid southern part of Xinjiang, China

(Fig. 1, Li et al., 2015). In recent years, it becomes a key national site for irrigation experiment in oasis. 
The land surface elevation is about $901 \mathrm{~m}$ above the mean sea level (Li et al., 2015). It is classified as a continental desert climate with an average annual precipitation of only $58 \mathrm{~mm}$ and maximum potential evaporation of $2788.2 \mathrm{~mm}$. The annual mean wind speed is $2.4 \mathrm{~m} / \mathrm{s}$ with the highest wind speed of 22 $\mathrm{m} / \mathrm{s}$. The annual mean temperature is $11.5^{\circ} \mathrm{C}$ with the minimum of $-30.9{ }^{\circ} \mathrm{C}$ and the maximum of 42.2 ${ }^{\circ} \mathrm{C}$. The depth to water table was ranged from $1.41 \mathrm{~m}$ to $2.43 \mathrm{~m}$ during the irrigation season from May to September 2012.

Cotton is one of the important fiber economic crops (Ashraf, 2002; Zhang et al., 2014a). From 2007 to 2011, cropping intensity of cotton in the word has increased (Valipour et al., 2015). Cotton fields occupy more than $50 \%$ of the total agricultural area of Kaidu-Kongqi River basin in Xinjiang, China (Zhang et al., 2014b). Cotton field irrigated with brackish water in the experimental site was about 2 hectares in size, and the surrounding fields have the same irrigation conditions. Thus the measurements of the experimental site can represent the typical irrigated cropland conditions in this region. Drip lines arrangement was set at the mode of "one mulch, two drip lines and four rows". The width of each plastic mulch was $110 \mathrm{~cm}$, and the no-mulch strip between a pair of mulches was $40 \mathrm{~cm}$. The spacing between drippers along the drip line was $30 \mathrm{~cm}$. Wide-rows zone, narrow-rows zone and no-mulch zone were defined according to the location of the cotton plants (Fig. 2a, Li et al., 2015). A drainage channel was set up for accepting the return flow of irrigation water to control the depth of groundwater table for avoiding secondary salinization. The lower boundary and the average water level of the drainage channel were respectively about 2 and $1.8 \mathrm{~m}$ to land surface during the irrigation season.

(Fig. 2b, Li et al., 2015).

\section{Field methods}

A duration of two irrigation periods at the flowering and bolling stages with the largest water 
demand was chosen for this study from 14 to 24 August, 2012. Meteorological data was collected by the Davis Wireless Vantage Pro2 weather station (Davis Instruments, California, USA). Microclimate factors, such as the light intensity, air temperature and humidity, wind speed and direction, dew point, barometric pressure, precipitation and solar radiation, were record.

120 soil samples were collected at twelve sub-plots to investigate soil texture (Fig. 2). For each plot, a soil borehole was set to obtain soil samples at 10, 20, 30, 40, 50, 60, 70, 80, 90, 100, 120, 130, 140 and $160 \mathrm{~cm}$ below the ground. The major soil type is loam; for a representative pot, the average texture percentages of sand, silt and clay are 46.81, 45.96 and 7.23, respectively (Li et al., 2015). A monitoring well was drilled to measure the dynamic water table (Fig. 2). For an irrigation day, water table was measured every two hours from 8:00 to 8:00 of the next day; but for other days of the experiment period, the water table was record from 8:00 to 20:00 of the day (Beijing time). There was no precipitation during the experiment period, and the amount of irrigation water on 15 August and 20 August were $45.6 \mathrm{~mm}$ and $45.0 \mathrm{~mm}$, respectively, according to the normal irrigation regime of the area. TDS of the brackish water used for irrigation was $2.4 \mathrm{~g} \mathrm{~L}^{-1} .10 \mathrm{~g} \mathrm{~m}^{-2}$ of urea was applied into the cotton filed at the second irrigation event of the experimental period. The mean volumetric water content nearby the water table was 0.28 and the saturated water content was 0.4 , which were directly determined in the laboratory by drying the known volume of undisturbed soil columns. The soil water near water table was collected by soil moisture sampler, and the TDS was $7.1 \mathrm{~g} \mathrm{~L}^{-1}$.

\subsection{Calculation of ET}

Though many empirical methods are convenient to calculate the reference evapotranspiration, especially for the regions with limited weather data (Valipour, 2014c; Valipour and Eslamian, 2014; Valipour, 2015b, 2015c, 2015d, 2015e, 2015f), based on the variously recorded meteorological data in 
this study, Penman-Monteith model recommended by Food and Agriculture Organization of the United Nations (FAO) was selected for reference evapotranspiration estimation $\left(E T_{0}\right)$ and can be expressed as (Allen et al., 1998)

$$
E T_{0}=\frac{0.408 \Delta\left(R_{n}-G\right)+\gamma \frac{37}{T_{h r}+273} u_{2}\left(e^{0}\left(T_{h r}\right)-e_{a}\right)}{\Delta+\gamma\left(1+0.34 u_{2}\right)}
$$

where $E T_{0}$ is the reference evapotranspiration $\left(\mathrm{mm} \mathrm{hour}^{-1}\right), R_{\mathrm{n}}$ is the net radiation at the grass surface $\left(\mathrm{MJ} \mathrm{m}^{-2}\right.$ hour $\left.^{-1}\right), G$ is the soil heat flux density $\left(\mathrm{MJ} \mathrm{m}^{-2}\right.$ hour-1), $T_{h r}$ is the mean hourly air temperature $\left({ }^{\circ} \mathrm{C}\right), \Delta$ is the saturation slope vapor pressure curve at $T_{h r}\left(\mathrm{kPa}^{\circ} \mathrm{C}^{-1}\right), \gamma$ is the psychrometric constant $\left(\mathrm{kPa}^{\circ} \mathrm{C}^{-1}\right), e^{0}\left(T_{h r}\right)$ is the saturation vapor pressure at air temperature $T_{h r}(\mathrm{kPa}), e_{a}$ is the average hourly actual vapor pressure $(\mathrm{kPa})$, and $u_{2}$ is the average hourly wind speed $\left(\mathrm{m} \mathrm{s}^{-1}\right)$. Details for each parameter refers to Allen et al. (1998).

Using the crop coefficient approach, the potential crop ET of cotton $\left(E T_{\mathrm{p}}\right)$ can be calculated by multiplying the $E T_{0}$ by the crop coefficient of cotton $\left(K_{\mathrm{c}}\right)$ (Allen et al., 1998):

$$
E T_{\mathrm{p}}=K_{\mathrm{c}} E T_{0}
$$

where $E T_{\mathrm{p}}$ is the potential crop evapotranspiration $\left(\mathrm{mm} \mathrm{hour}^{-1}\right), K_{\mathrm{c}}$ is the crop coefficient of cotton (dimensionless) and $E T_{0}$ is the reference evapotranspiration $\left(\mathrm{mm} \mathrm{hour}^{-1}\right)$. Then the potential transpiration for cotton can be determined as

$$
T_{\mathrm{p}}=\left(1-e^{-k L A I}\right) E T_{\mathrm{p}}
$$

where $T_{p}$ is the potential transpiration $\left(\mathrm{mm} \mathrm{hour}^{-1}\right), k$ is the extinction coefficient, and $L A I$ is the leaf area index.

\subsection{ET measurement}

The portable system of respiration measurement (i.e., SRS-2000, made in ADC BioScientific Ltd, 
Hertfordshire, UK) equipped with a variety of leaf rooms was used to measure the transpiration of plant leaf and soil evaporation by switch different kinds of chambers. The measurements were carried out in an opened system configuration with fresh air passing through the chamber. The water flux was calculated from the differences of $\mathrm{H}_{2} \mathrm{O}$ concentration between the inflow gas (i.e., the reference level) and the passing through gas (i.e., the analysis level) for leaf and soil samples. Due to the difference between the gas concentration and velocity, the transpiration rate was calculated about every 20 seconds. The small fan in the chamber made the gas mixed around the sample. $\mathrm{H}_{2} \mathrm{O}$ concentration was measured by two high quality humidity sensors contained inside the chamber. Transpiration rate or net $\mathrm{H}_{2} \mathrm{O}$ exchanging rate of soil surface (evaporation rate) can be calculated by the following equation (ADC BioScientific Ltd., 2010).

$E\left(m m o l ~ \mathrm{~m}^{-2} \mathrm{~s}^{-1}\right)$ represents the transpiration rate of plant leaf or net $\mathrm{H}_{2} \mathrm{O}$ exchanging rate of soil surface (i.e., evaporation rate) as follow,

$$
E=\frac{\left(e_{a n}-e_{r e f}\right) u_{s}}{p}
$$

where $e^{\prime}{ }_{a n}$ is the water vapor pressure leaving the leaf chamber after dilution correction (mbar); $e_{\text {ref }}$ is the water vapor pressure entering the chamber (mbar); $u_{\mathrm{s}}$ is the mass flow of gas entering the chamber per square meter of the sample ( $\left.\mathrm{mmol} \mathrm{m}^{-2} \mathrm{~s}^{-1}\right) \cdot p$ is the atmospheric pressure (mbar).

The leaf transpiration and soil evaporation were measured every day at 9:00, 12:00, 15:00, 18:00 and 21:00 (Beijing time) from 14 August to 24 August. Four different positions of representative plants and no-mulch zones were selected as repeating treatment. For each plant, considering the plant canopy structures, three sunlit leaves of the top, middle, and lower layers were selected for leaf transpiration measurement. Five samples for a leaf or no-mulch position were measured at each time and the mean value was considered as the representative transpiration or soil evaporation rate. 
Given the small amount of water demand at night, soil water could well meet the situation, and $T_{p}$ could be viewed as the corresponding transpiration at night. To obtain the cotton transpiration of a whole plant from the leaf transpiration measured by SRS-2000, an appropriate upscale method was needed. A simple method of multiplying the average transpiration of a unit leaf area by the total plant leaf area could be used. However, this would induce significant errors due to the variability for leaf transpiration of a cotton plant and differences between the shade and sunlit leaves (Petersen et al., 1992; Zhang et al., 2014a). In this study, the cotton transpiration at a unit area is estimated as (Zhang et al., 2014a)

$$
M_{p}=6.48 \times 10^{-2} \sum_{1}^{m}\left\{M_{l}\left(\alpha_{l} A_{l}\right)+\left[\left(M_{l} \beta_{l}\right)\left(1-\alpha_{l}\right) A_{l}\right]\right\}
$$

where $M_{p}$ is the transpiration rate on per unit area of the filed $\left(\mathrm{mm} \mathrm{hour}^{-1}\right), m$ is the number of canopy layers (denoted $l, 1$ to $\mathrm{m}), M_{l}$ is the measurement value for a sunlit leaf of the $k$ layer $\left(\mathrm{mmol} \mathrm{m}^{-2} \mathrm{~s}^{-1}\right), \alpha_{l}$ and $\beta_{l}$ are the ratio of a sunlit leaf area to the total leaf area and the ratio of transpiration rate of a shaded leaf to that of a sunlit leaf for the $l$ layers respectively, $A_{l}$ is the leaf area of the $l$ layer $\left(\mathrm{cm}^{2}\right)$, and $6.48 \times 10^{-2}$ is the unit conversion factor.

\subsection{Water-table fluctuation method (WTF)}

Water-table fluctuation method (WTF), about which a detail discussion was made by Healy and Cook (2002), is widely used for estimating recharge to groundwater (e.g., Rai et al., 1994; Kendy et al., 2004; Loheide et al., 2005; Delin et al., 2007; Park and Parker, 2008; Obuobie et al., 2012 and others). The advantage of the method is to avoid being influenced by the mechanism of water moving through the unsaturated zone, and the presence of preferential flow paths within the vadose zone in no way restricts its application (Healy and Cook, 2002). The information of specific yield and variation of water table of a period is needed in this method. However, the uncertainty results from the accuracy of 
specific yield and the valid inherent assumptions existed. Only if the recharge water arriving at the water table is significantly distinguished from the water that is transported away from the water table, could the method be used.

The WTF method was based on the premise that the rises of groundwater table were resulted from recharge water. Recharge rate $\left(R_{\mathrm{g}}^{\prime}, \mathrm{mm}\right.$ hour $\left.^{-1}\right)$ can be expressed as (Healy and Cook, 2002)

$$
R_{g}^{\prime}=S_{y} \frac{d h}{d t}=S_{y} \frac{\Delta h}{\Delta t}
$$

where $S_{y}$ is the specific yield, $h$ is the water table height (mm), and $t$ is the time (hour) in this study.

Due to the soil structure of loam and the shallow groundwater table, there were two obvious fluctuations during the two irrigation periods in this study, as shown in Fig. 3, and the downward water flow from irrigation water below the divergent surface of zero flux arrived at the water table soon after the irrigation events ( $\mathrm{Li}$ et al., 2015). Taking an irrigation period for example, the water table was lower at the beginning of irrigation, but began to respond and rise some hours after the end of the irrigation event. The largest recharge to groundwater appeared at the time of about two days after the irrigation, at which the groundwater level rose to the maximum and then began to decrease. These situations therefore were appropriate for using WTF.

To successfully use the WTF method, $S_{y}$ is a crucial parameter that should be carefully identified. Meinzer (1923) defined $S_{y}$ with no dimension as the ratio of the volume of water yield from saturated rock or soil by gravity to the own volume this rock or soil, and $S_{y}$ is generally defined as (Healy and Cook, 2002)

$$
S_{y}=\phi-S_{r}
$$

where $\phi$ is the porosity, and $S_{r}$ is the specific retention (the volume of water retained by the rock per unit volume of rock) which is equal to the field capacity for soil scientists. 
Because of the time lag caused by gravity drainage and the short period of the water-table fluctuation, the actual water retention near the water table was greater than that of the $S_{r}$. In other words, the $S_{y}$ in this situation was lower than the real one. The $S_{y}$ in fact varies with the depth to the water table and the soil-water retention curve should be taken into account (Childs, 1960; Healy and Cook, 2002). But for fine sand and a silt loam, Duke (1972) suggested $S_{y}$ be calculated as below

$$
S_{y}=\phi-\theta(H)
$$

where $\theta$ is the water content $\left(\mathrm{cm}^{3} \mathrm{~cm}^{-3}\right)$, and $H$ is the depth to water table $(\mathrm{cm})$.

$\Delta h$ could be calculated by the difference between peak value of water table and the inferred antecedent recession curve at the time of the peak as shown in Fig. 4 (Delin et al., 2007). To use the WTF method, main approaches are the graphical approach and the master recession curve (MRC), and the third one is based on a computer code from the RISE program. Compared to the MRC and RISE approaches that requires a series of continuously measured water levels, the graphical approach is relatively flexible (Delin et al., 2007). In graphic approach, the antecedent recession curve was extrapolated manually to get $\Delta h$ based on the water-level variations, which could avoid being influenced by some invalid input to obtain the reasonable water-table fluctuations. It was obvious that results of the graphic approach involved more subjectivity than other approaches and would produce slight difference from different users (Delin et al., 2007). For the irrigation day of an irrigation period, water table was measured every two hours from 8:00 to 8:00 of the next day; but for other days of the experiment period, the water table was record from 8:00 to 20:00 of a day. Thus the measured water levels were not continuous with the time duration. Due to the relatively little data of the short experimental time, the graphical approach, which was more flexible and convenient than others for using, was chosen in this study. 
Water-level fluctuations are not only caused by precipitation and irrigation, but also some other sources, such as lateral flow, electrical surges, changes in barometric pressure, pumping, earth tide effects, entrapped air, temperature variations, and manual adjustment to the water-level measuring device (Delin et al., 2007). All these factors may cause some errors in recharge estimation. Taking Lisse effect as an example, the phenomenon, which is a kind of unreal recharge, is due to the trapped air by high intensity infiltration water. The air pressure increases and the water table in monitoring well rises to compensate for the increasing pressure of the unsaturated zone when the infiltration moved downward in the soil profile (Heliotis and DeWitt, 1987). The water table rises disproportionately to the quantity of infiltration water, and after some time the water-level raise caused by the Lisse effect would disappear. Thus the Lisse effect exaggerates the recharge of infiltration water as shown in Fig. 5 (Crosbie et al., 2005). During the experimental period of ten days in this study, recession of the regional water table or lateral flow of groundwater was relatively stable, which could be distinguished from the recharge of drip irrigation. The graphic approach for WTF was suggested to be as the following way. For the two fluctuation periods of water level, the two antecedent recession curves, which were parallel to each other, were extrapolated respectively. $\Delta h$ for the second irrigation period was estimated by the difference of the two parallel lines. The noise of other inputs could be avoided in this way, and the difference of the two parallel lines was constant between the two adjacent fluctuation periods.

\section{Results}

\subsection{ET under mulched drip irrigation}

Crop coefficient of cotton at flowering and bolling stages is suggested to be 1 at the experimental site (Gao, 2009), and the potential ET of the cotton field $\left(\mathrm{ET}_{\mathrm{p}}\right)$ is thus equal to $E T_{0}$ according to Eq. (1). 
The parameter $k$ and $L A I$ in Eq. (3) for cotton of the experimental site at flowering and bolling stages is 0.858 and 3.1 , respectively $(\mathrm{He}, 2010)$. The daily potential transpiration was the sum of $T_{p}$ for 24 hours (Table 1). The potential evaporation could be obtained by the calculation of $E T_{0}$ minus $T_{p}$.

The dynamics of leaf transpiration at different measure times during the experimental period were showed in Fig. 6, which showed that the maximum and minimum in a day for leaf transpiration appeared at noon and at morning and dusk, respectively. The nighttime leaf transpiration at evening was small and always neglected in some literatures (Wang et al., 2007; Zhang et al., 2007a). As shown in Fig. 7, the transpiration rate in a day for the top layer leaves was obvious larger than for the middle and lower layer leaves at noon. In addition, the daily maximum transpiration rate after an irrigation was higher than that before an irrigation, which could be attributed to the high soil moisture from the inputted irrigation water.

The cotton canopy was divided into three layers (i.e., $m=3$ ), and the total leaf area per unit field could be inferred from the LAI. Other parameters were set according to Zhang et al. (2014a) listing in Table 2. The ratio $(\alpha)$ of sunlit leaf area to total leaf area is the largest for the top layer, and the smallest for the lower layer, except the time of 21:00 when a day is near the dusk. In a day, furthermore, $\alpha$ firstly increases peaking at noon (around 15:00), and then decreases in the afternoon.

Transpiration rate at each measure time could be calculated by Eq. (5). The mean value of the five measure samples, multiplied 12 hours to get the transpiration of a daytime. Nighttime the actual transpiration was considered equal to $T_{p}$, and the daily transpiration was thus the sum of two parts at the day and nighttime, as shown in Table $1\left(T_{\mathrm{SRS}-2000}\right)$. Results indicated that the calculated $T_{\mathrm{SRS}-2000}$ was larger than the $T_{p}$, and the main error for this abnormal phenomenon generated from the upscale conversion method and system measurement errors of the SRS-2000. A study made by Zhang et al. 
(2007b) showed that transpiration rate measured by sum of leaf transpiration was larger than that of the weighting method for a whole plant.

Soil moisture was at a high level on the first two days after an irrigation event in general, and the actual cotton transpiration rate $(T)$ was considered to be equal to the $T_{p}$. The estimated transpiration rate, which was convert from the measured results of SRS-2000, had a significant linear relation with $T_{p}$ (Fig. 8). Thus the $T$ of the days could be inferred from conversion method of the measured values:

$$
T=0.3717 M_{p}+0.0258, \quad \mathrm{R}^{2}=0.749
$$

where $T$ is the actual transpiration rate $\left(\mathrm{mm} \mathrm{hour}^{-1}\right), M_{p}$ is the estimated transpiration rate per unit area of the field by conversion method $\left(\mathrm{mm} \mathrm{hour}^{-1}\right)$.

Eq. (9) was also appropriate for estimating $T$ of a whole irrigation period due to the stability of SRS-2000, and the actual transpiration obtained by this way was shown in Table 1 as $T_{\mathrm{c}}$. Although the estimated transpiration rate for the first two days after an irrigation event had some deviances with the $T_{p}$ (Fig. 8), their linear relation justified the measured results of SRS-2000. For the two irrigation periods of ten days, the total $T_{\mathrm{c}}$ was $30.7 \mathrm{~mm}$. In addition, the $T_{p}$ of $2.72 \mathrm{~mm}$ and $T_{\mathrm{SRS}-2000}$ of $3.81 \mathrm{~mm}$ on 23 August were obvious lower than that on 22 and 24 August with $T_{p}$ of $4.0 \mathrm{~mm}$ and $4.96 \mathrm{~mm}$, and $T_{\mathrm{SRS}-2000}$ of $7.41 \mathrm{~mm}$ and $6.45 \mathrm{~mm}$ respectively (Table 1). Fig. 6 and Fig. 7 also show the lower transpiration rate on 23 August, which may result from the lower solar radiation of $2629 \mathrm{~W} \mathrm{~m}^{-2}$ on 23 August, relative to that of $5724 \mathrm{~W} \mathrm{~m}^{-2}$ and $6042 \mathrm{~W} \mathrm{~m}^{-2}$ on 22 and 24 August respectively.

For mulched drip irrigation, the mulched film prevents the water flux of wide-row and narrow zones and the soil water content at no-mulch zone is very low in general (Wang et al., 2001; Bonachela et al., 2001; Zhang et al., 2014a). In addition, the high LAI of 3.1 indicated a fully closed canopy and strong root-water uptake for transpiration at flowering and bolling stages. Thus the soil evaporation 
was expected to be a small portion of ET (Zhang et al., 2014a). Comparison of Fig. 6 and Fig. 9 indicated that the transpiration rate was much greater than the soil evaporation rate. The ratio of average transpiration rate to soil evaporation rate was 34. During the experimental period, transpiration and soil evaporation were measured synchronously. Meanwhile, soil evaporation at night was so small that it was considered to be the potential evaporation. Compared with the measurement of leaf transpiration, the chamber of SRS-2000 was covered with a certain area on the soil surface, thus no upscale method was needed and the soil surface evaporation equaled to the water flux measured by SRS-2000. Considering that the ratio of $4 / 15$ of the bare strips to the field area, the estimated daily soil evaporation for the field was $4 / 15$ of that measured by SRS-2000 as shown in Table $1\left(E_{\text {SRS-2000). The }}\right.$ total soil evaporation was $0.4 \mathrm{~mm}$ for the two irrigation periods, and ET $(31.1 \mathrm{~mm})$ was the sum of the total actual transpiration and soil evaporation the of the experimental period of ten days, in which

$98.6 \%$ was the plant transpiration.

\subsection{Recharge to groundwater from mulched drip irrigation}

The texture of experimental soil was loam with a high percentage of sand and silt, thus Eq. (8) was appropriate for $S_{y}$ estimation. $\phi$ was considered to be the saturated water content, and the mean value of $\theta(H)$ near the water table was 0.28 obtained by drying method. The measured saturated water content was 0.40 , thus the $S_{y}$ was 0.12 which was equal to 0.40 minus 0.28 .

$\Delta h$ for the second irrigation period was estimated by the difference of the two parallel lines, which was $22.5 \mathrm{~cm}$ of $\mathrm{H}_{1}$ minus $\mathrm{H}_{3}$ as shown in Fig. 3. Recharge of the second irrigation period of five days to groundwater was $27 \mathrm{~mm}$ calculated by the Eq. (6). Likewise, the recharge of the first irritation event was $21.2 \mathrm{~mm}$. Total recharge was $48.2 \mathrm{~mm}$ during the two irrigation periods of ten days. Water requirement in the experimental period could be considered as the ET of $31.1 \mathrm{~mm}$. The ratio of 
recharge, resulting from deep percolation of irrigation, to water requirement of cotton was 1.55 . The total amount of irrigation water of $90.6 \mathrm{~mm}$ at the two irrigation periods was 2.92 times of ET. All of these showed that the severe excessive amount of irrigation water of $90.6 \mathrm{~mm}$ was applied in the present irrigation regime resulting in a large deep percolation of $48.2 \mathrm{~mm}$ at the two irrigation periods of ten days.

\section{Discussion}

\subsection{Error analysis}

Dimension conversion of leaf scale to field scale of per unit area was the main error source for determining transpiration. Because the number of samples measured by SRS-2000 was limited, due to the large number of leaves with considerable variability in a field. The limited number of leaf samples may result in insufficient representativeness and sometimes do not completely capture the variance and the mean response of the overall situation for upscaling operation (Loranty et al., 2008; Zhang et al., 2014a). The canopy parameters and the ratio of the transpiration rate to a shaded leaf to that of a sunlit leaf, which referenced from literatures would also make some errors to actual situation (Petersen et al., 1992, Thanisawanyangkura et al., 1997). The simultaneous measurements of canopy structure and leaf transpiration are expected to improve the results (Zhang et al., 2014a). In addition, the measurement of SRS-2000 can also be affected by the drug quality of the equipment and other systematic bias to some extent.

In application of the water-table fluctuation method (WTF), the water table difference is obtained by manually extrapolating the antecedent recession curve in the graphical approach, which could avoid being influenced by some invalid input to obtain the reasonable water-table fluctuations. However, this approach would also involve some subjectivity that could produce slight difference from different users 
(Delin et al., 2007). And if a great number of water fluctuations happen in some situations, the workload of the graphical approach would be arduous. Furthermore, $S_{y}$ was given as a mean value in the calculation period resulting in a certain degree of errors. The $S_{y}$ was not enough to represent each point of the soil profile, because the random variation might happen at different time and depth of water table. Meanwhile, the $S_{y}$ is not representative for the whole scale of the chosen filed (Rohde et al., 2015). A great number of monitoring profiles are needed to precisely estimate the recharge due to drip irrigation at a larger scale of the region. In addition, the WTF method has some other limitations. Deep water table may not display sharp rise because wetting fronts tend to disperse over long distances, and the method cannot be used for the steady recharge (Healy and Cook, 2002). If the recharge rate is constant and equal to the discharge away from the water table, the WTF would predict no recharge (Healy and Cook, 2002). Nonetheless, drip irrigation is usually pulse recharge with a short period, such as 5-d frequency ( $\mathrm{Li}$ et al., 2015), and this would rarely result in a steady recharge rate.

\subsection{Composition of the recharge}

Due to the relatively short experimental period, the gradient of groundwater water table in the region could be seen at a relatively stable status, and the inflow equaled to the outflow. Rasmussen and Andreasen (1959) gave a modified equation of water budget, in which the recharge to groundwater included three parts (Healy and Cook, 2002):

$$
R_{g}=\Delta S^{g w}+Q^{b f}+E T^{g w}
$$

where $R_{g}$ is the recharge to groundwater $(\mathrm{mm}), \Delta S^{g w}$ is the change in storage in the saturated zone $(\mathrm{mm})$,

$Q^{b f}$ is the base flow (mm), and $E T^{g w}$ is the evaporation from groundwater (mm).

Though ET was strong at the experimental period of the flowering and bolling stages, the amount of irrigation water was much greater than it, as shown above. The authors' previous research indicated 
no groundwater evaporation of $E T^{g w}$ occurred, due to the downward water flow below the divergent curved surface of zero flux in soil profile before irrigation (Li et al., 2015). Thus $R_{g}$ had only two parts of $\Delta S^{g w}$ and $Q^{b f} . Q^{b f}$ in this study was the base flow of the drainage channel, and equaled to the returned irrigation water through lateral flow seepage into the drainage channel. $\Delta S^{g w}$ was calculated through $S_{\mathrm{y}} \Delta h_{n}$, where $\Delta h_{n}$ could be a net change in head of $\mathrm{H}_{1}$ minus $\mathrm{H}_{2}$ for a water table rising duration. $\Delta S^{g w}$ obtained by graphical approach was $26.1 \mathrm{~mm}$ at the two irrigation periods, and the $Q^{b f}$ was $22.1 \mathrm{~mm}$ of 48.2 minus $26.1 \mathrm{~mm}$. It could be concluded that the seepage flow from returned irrigation water occupied $45.9 \%$ of the total recharge to groundwater. But for the regional scale at the drip irrigation season, recharge to groundwater increases the lateral flow out of the oasis zone to the desert or the lake

(Zhang et al., 2014b).

\subsection{Soil water and salt budget}

Based on the law of conservation of mass, soil water and salt budgets in this study were defined as the input and output of the water and salt for a soil column of certain area from soil surface to water table during the two irrigation periods. Fig. 10 shows the 3-d conceptual model of mulched drip irrigation. The groundwater water was recharged by irrigation water, and there was no precipitation during the experimental period. The equation of water budget could be then expressed as

$$
\Delta W=I-E-T-R_{g}
$$

where $\Delta W$ is the variation of water storage $(\mathrm{mm}), I$ is the amount of irrigation water $(\mathrm{mm}), E$ is the soil evaporation ( $\mathrm{mm}), T$ is the plant transpiration $(\mathrm{mm})$, and $R_{g}$ is the recharge to groundwater $(\mathrm{mm})$. The budget results were shown in Table 3. According to the measurement and estimated results of above statement, $I$ was $90.6 \mathrm{~mm}, E$ was $0.4 \mathrm{~mm}, T$ was $30.7 \mathrm{~mm}$, and $R_{g}$ was $48.2 \mathrm{~mm}$. The $\Delta W$ obtained by Eq. (11) was $11.3 \mathrm{~mm}$, indicating an increasing soil water storage during the two irrigation periods. $R_{g}$ 
accounted for $53.2 \%$ and the variation of water storage accounted for $12.5 \%$, however, the ET was only $34.3 \%$ of the irrigation water, indicating a severe excessive irrigation at flowering and bolling stages of cotton in this site.

According to the equation of water budget and the amount of applied fertilizer, the salt budget could be expressed as the following equation:

$$
\Delta S=I C_{i}+S_{f}-R_{g} C_{g}
$$

where $\Delta S$ is the variation of salt storage of soil profile $\left(\mathrm{g} \mathrm{m}^{-2}\right), S_{f}$ is the applied fertilizer $\left(\mathrm{g} \mathrm{m}^{-2}\right), C_{i}$ is the TDS of irrigation water $\left(\mathrm{g} \mathrm{m}^{-3}\right), C_{g}$ is the TDS of soil water near water table $\left(\mathrm{g} \mathrm{m}^{-3}\right)$. According to the measurement results, $S_{f}$ was $10 \mathrm{~g} \mathrm{~m}^{-2}, C_{i}$ was $2400 \mathrm{~g} \mathrm{~m}^{-3}$, and $C_{g}$ was $7100 \mathrm{~g} \mathrm{~m}^{-3}$.

A minus sign was given before $R_{g} C_{g}$ at right side of the Eq. (12), for the water flowed out of soil profile. Considering the short calculation time, salt precipitation in cotton plant could be neglected. In other words, the input salt items were from the brackish irrigation water and applied fertilizer, and the output salt item was brought out by the deep percolation into groundwater. The calculated results listed in Table 3 show that the input salt form irrigation water and applied fertilizer was $227 \mathrm{~g} \mathrm{~m}^{-2}$, the output was $342 \mathrm{~g} \mathrm{~m}^{-2}$, and $\Delta S$ was $-115 \mathrm{~g} \mathrm{~m}^{-2}$. From the view of salt budget, salt was leached into saturated zone (groundwater) by large amount of irrigation water of $90.6 \mathrm{~mm}$ in this study, and soil profile was therefore in a state of desalination. The amount of output salt was 1.56 times of the input, and the salt of $115 \mathrm{~g} \mathrm{~m}^{-2}$ was leached out of the soil profile at the two irrigation periods. In other words, the salt did not always accumulate in soil profile under mulched drip irrigation using brackish water. If the brackish water was applied at a large amount, the salt with recharge to groundwater might be more than the input from irrigation water.

Immediately after irrigation, the soil profile is with the maximum water content and minimal salt 
concentration. Then the water is lost by evaporation and crop transpiration and most of the salts are left behind in the top soil and root zone. The soil becomes drier and the salt concentration becomes higher before the next irrigation (Maas and Hoffman, 1977). For mulched drip irrigation mode, irrigation with a certain period is needed to leach excessive salt out of the root zone and provide soil conditions with a tolerable salinity level for cotton growth. High salinity strips are formed along the wetting front and at the bare soil surface under soil-water flow system of mulched drip irrigation (Li et al., 2015, Fig. 11). In addition, as shown in Fig. 11a, the small water content at the zone of no mulch between plastic films results in the little amount of soil evaporation (Zhang et al., 2014a). The waste water also had potential in threatening sustainable utilization of brackish water resources in arid areas, although large irrigation water was helpful for salt leaching. The pesticides and fertilizer in soil profile could also be leached into groundwater with deep percolation of irrigation water, resulting in terrible groundwater pollution.

On the other hand, the rising of saline water table resulting from the deep percolation of irrigation water aggravated the risk of secondary salinization under strong evaporation. In a word, there is a large optimum space for the soil water and salt management in the oasis region, which needs to be further studied.

\section{Summary and conclusions}

Mulched drip irrigation with brackish water represents a typical pattern of using saline water for agriculture in arid regions with intense evaporation and scarce precipitation. Though freshwater resources are shortage, the shallow brackish water may widely distribute in these regions. The reasonable and safe use of brackish water has become a core issue. Capitalizing on recent progress in evapotranspiration measurement techniques and water-table fluctuation methods, the evapotranspiration and recharge to groundwater could be quantified, thus gaining a better 
understanding of soil water and salt budgets under mulched drip irrigation to support sustainable using of brackish water in future. The insight of this study could be potentially applied to other arid inland regions, such as the Central Asia (Valipour, et al., 2015), and provide data and precedent for further study on the water cycle and ecological process in micro-irrigated farmland.

In this study, experiments of mulched drip irrigation with brackish water for a cotton field were carried out during two irrigation periods at flowering and bolling stages, in which large amount of water requirement were needed for cotton growth. A group of upscaling conversion methods was used to quantify the actual evapotranspiration (ET) of a unit area. By measuring the transpiration on a leaf scale and considering the canopy structure, the upscaling methods could help other researchers estimate field evaporation from point measurements (Zhang et al., 2014a). On the days of just after irrigation events, the measured transpiration had a significant positive relationship with the potential transpiration that was approximate to actual transpiration, and this could be used to estimate the transpiration during a whole irrigation period. In addition, the soil evaporation was directly measured by the equipment. Results showed that the total ET of the two irrigation periods at flowering and bolling stages was 31.1 $\mathrm{mm}$, with soil evaporation of $0.4 \mathrm{~mm}$, and transpiration of $30.7 \mathrm{~mm}$ accounted for $98.6 \%$ of the ET. The high fraction of transpiration might support the popularization of mulched drip irrigation in other arid and semi-arid regions in the future to address the challenge of water scarcity (Zhang et al., 2014a).

The short-term fluctuations of water table varied with irrigation events, which attributed to anthropogenic activities of mulched drip irrigation in this study, might result from the shallow water table and the soil texture with large hydraulic conductivity. Thus the water-table fluctuation (WTF) method was used to estimate the recharge to groundwater. Given the inconsecutive monitoring of water levels, the water table difference was obtained by manually extrapolating the antecedent recession 
curve in the graphical approach, which had the advantage of without being influenced by some invalid input to obtain the reasonable water-table fluctuations. Based on the calculated evapotranspiration and recharge to groundwater, soil water and salt budget were discussed. The amount of recharge was 48.2 $\mathrm{mm}$, in which $22.1 \mathrm{~mm}$ was seepage into the drainage channel. For the irrigation water applied in the cotton field, $34.3 \%$ of which was ET or the water requirement for cotton growth, and the variation of water storage accounted for $12.5 \%$, but deep percolation of recharge to groundwater accounted for $53.2 \%$, indicating a severe water losing. The present regime of mulched drip irrigation was useless for sustainable utilization of brackish water resources in arid areas. Results of the salt budget showed that the output salt was 1.56 times of the input, and large amount of salt of $115 \mathrm{~g} \mathrm{~m}^{-2}$ was leached out of soil profile at the two irrigation periods. This proves that the accumulated salt could be effectively leached out of soil profile under large amount of irrigation with brackish water of $90.6 \mathrm{~mm}$ in this study.

We put forward a practice of estimating evapotranspiration and recharge to groundwater in the cotton field that was serviced by mulched drip irrigation using brackish water, and then the soil water and salt budget could be discussed. However, effectual management for soil water and salt regulation, and the optimum soil environment for cotton growth still need to be further studied. Huge amount of pesticides and fertilizer are applied in cotton field. If drainage fraction is high, these chemicals would find their way to the groundwater. To check their migration to groundwater, there is scope for more work, in particular the mathematical model that should be calibrated to substantiate the information collected from the measurements.

\section{Acknowledgements}

This research was funded by the National Science Foundation of China (41172218, 41502225 and 
U1403282). We gratefully acknowledge the Irrigation Experiment Station of Korla for providing working space and housing. We also thank Dr. Ying Liu for her language assistance.

\section{References:}

ADC Bioscientific Ltd., 2010. LCpro+ portable photosynthesis system: instruction mannual, ADC BioScientific Ltd., Hertfordshire, UK.

ADC BioScientific Ltd. LCpro+ Portable Photosynthesis System: Instruction mannual[R].

Allen, R.G., Pereira, L.S., Raes, D., Smith, M., 1998. FAO Irrigation and drainage paper No. 56. Rome: Food and Agriculture Organization of the United Nations, 26-40.

Aragüés, R., Medina, E.T., Zribi, W., Clavería, I., Álvaro-Fuentes, J., Faci, J., 2015. Soil salinization as a threat to the sustainability of deficit irrigation under present and expected climate change scenarios. Irrig. Sci. 33(1), 67-79.

Ashraf, M., 2002. Salt tolerance of cotton: Some new advances. Crit. Rev. Plant Sci. 21(1): 1-30.

Assouline, S., Moller, M., Cohen, S., Ben-Hur, M., Grava, A., Narkis, K., Silber, A., 2006. Soil-plant system response to pulsed drip irrigation and salinity: Bell pepper case study. Soil Sci. Soc. Am. J. 70(5), 1556-1568.

Bhattarai, S.P., Midmore, D.J., Pendergast, L., 2008. Yield, water-use efficiencies and root distribution of soybean, chickpea and pumpkin under different subsurface drip irrigation depths and oxygation treatments in vertisols. Irrig. Sci. 26(5), 439-450.

Bonachela, S., Orgaz, F., Villalobos, F.J. and Fereres, E., 2001. Soil evaporation from drip-irrigated olive orchards. Irrig. Sci. 20(2): 65-71. 
Chen, W.P., Hou, Z.N., Wu, L.S., Liang, Y.C., Wei, C.Z., 2010. Evaluating salinity distribution in soil irrigated with saline water in arid regions of northwest China. Agr. Water Manage. 97(12), 2001-2008.

Childs, E.C., 1960. The nonsteady state of the water table in drained land. J. Geophys. Res. 65(2), 780-782.

Crosbie, R.S., Binning, P., Kalma, J.D., 2005. A time series approach to inferring groundwater recharge using the water table fluctuation method. Water Resource Res. 41(1).

Danierhan, S., Shalamu, A., Tumaerbai, H., Guan, D.H., 2013. Effects of emitter discharge rates on soil salinity distribution and cotton (Gossypium hirsutum L.) yield under drip irrigation with plastic mulch in an arid region of Northwest China. J. Arid Land 5(1), 51-59.

Delin, G.N., Healy, R.W., Lorenz, D.L., Nimmo, J.R., 2007. Comparison of local-to regional-scale estimates of ground-water recharge in Minnesota, USA. J. Hydrol. 334(1), 231-249.

Duke, H. R., 1972. Capillary properties of soils-influence upon specific yield. Amer. Soc. Agr. Eng. Trans. ASAE 15, 688-691.

Gao, L., 2009. Study on the regulation of salt and water transport in cotton field under mulched drip irrigation condition. Tsinghua university, Beijing, China (in Chinese with English abstract).

Hamed, Y., 2008. Soil structure and salinity effects of fish farming as compared to traditional farming in northeastern Egypt. Land Use Policy 25(3), 301-308.

He, Y., 2010. Soil water and salt regulation of cotton field under mulched drip irrigation of brackish water in arid zones. China University of Geosciences, Wuhan, China (in Chinese with English abstract)

Healy, R.W., Cook, P.G., 2002. Using groundwater levels to estimate recharge. Hydrogeol. J. 10(1), 
91-109.

Heliotis, F.D., DeWitt, C.B., 1987. Rapid water table response to rainfall in a northern peatland ecosystem. J. Am. Water Resour. As. 23(6), 1011-1016.

Kendy, E., Zhang, Y., Liu, C., Wang, J., Steenhuis, T., 2004. Groundwater recharge from irrigated cropland in the North China Plain: case study of Luancheng County, Hebei Province, 1949-2000. Hydrol. Process, 18(12), 2289-2302.

Letey, J., Hoffman, G.J., Hopmans, J.W., Grattan, S.R., Suarez, D., Corwin, D.L., Oster, J.D., Wu, L., Amrhein, C., 2011. Evaluation of soil salinity leaching requirement guidelines. Agr. Water Manage. 98(4), 502-506.

Li, X., 2003. Pressure of water shortage on agriculture in arid region of China. Chinese Geogr. Sci. 13(2), 124-129.

Li, X., Jin, M., Huang, J. and Yuan, J., 2015. The soil-water flow system beneath a cotton field in arid north-west China, serviced by mulched drip irrigation using brackish water. Hydrogeol. J. 23(1): $35-46$.

Li, X., Yang, J., Liu, M., Liu, G., Yu, M., 2012. Spatio-temporal changes of soil salinity in arid areas of south Xinjiang using electromagnetic induction. J. Integr. Agr. 11(8), 1365-1376.

Liu, M.X., Yang, J.S., Li, X.M., Yu, M., Wang, J., 2012. Effects of irrigation water quality and drip tape arrangement on soil salinity, soil moisture distribution, and cotton yield (Gossypium hirsutum L.) under mulched drip irrigation in Xinjiang, China. J. Integr. Agr. 11(3), 502-511.

Loheide, S.P., Butler, J.J., Gorelick, S.M., 2005. Estimation of groundwater consumption by phreatophytes using diurnal water table fluctuations: A saturated-unsaturated flow assessment. Water Resour. Res. 41(7), W7030. 
Loranty, M.M., Mackay, D.S., Ewers, B.E., Adelman, J.D., Kruger, E.L., 2008. Environmental drivers of spatial variation in whole-tree transpiration in an aspen-dominated upland-to-wetland forest gradient. Water Resour. Res. 44(2), W024412.

Maas, E.V. and Hoffman, G.J., 1977. Crop Salt Tolerancel-Current Assessment. J. Irrig. Drain. Divis. 103(2): 115-134.

Marouelli, W.A., Silva, W., 2007. Water tension thresholds for processing tomatoes under drip irrigation in Central Brazil. Irrig. Sci. 25(4), 411-418.

Meinzer, O.E., 1923. The occurrence of ground water in the United States with a discussion of principles. University of Chicago. US Geol. Surv. Water Supply Pap. 489, 321.

Mirjat, M.S., Mughal, A.Q., Chandio, A.S., 2014. Simulating water flow and salt leaching under sequential flooding between subsurface drains. Irrig. Drain. 63(1), 112-122.

Niu, W.Q., Wu, P.T., Li, J., Shao, H.B., 2010. One of frontiers in agricultural and environmental biotechnology for the arid regions: Micro-pressure drip irrigation technology theory and practices. Afr. J. biotechnol. 9(20), 2891-2897.

Obuobie, E., Diekkrueger, B., Agyekum, W., Agodzo, S., 2012. Groundwater level monitoring and recharge estimation in the White Volta River basin of Ghana. J. Afr. Eerth Sci. 71-72, 80-86

Oron, G., DeMalach, Y., Gillerman, L., David, I., Lurie, S., 2002. Effect of water salinity and irrigation technology on yield and quality of pears. Biosyst. Eng. 81(2), 237-247.

Panigrahi, P., Sharma, R.K., Parihar, S.S., Hasan, M., Rana, D.S., 2013. Econonica analysis of drip-irrigated kinnow mandarin orchard under deficit irrigation and partial root zone drying. Irrig. Drain. 62(1), 67-73.

Park, E., Parker, J.C., 2008. A simple model for water table fluctuations in response to precipitation. J 
Hydrol. 356(3): 344-349

Petersen, K.L., Fuchs, M., Moreshet, S., Cohen, Y., Sinoquet, H., 1992. Computing transpiration of sunlit and shaded cotton under variable water water-stress. Agron. J. 84(1), 91-97.

Rai, S.N., Manglik, A., Singh, R.N., 1994. Water table fluctuation in response to transient recharge from a rectangular basin. Water Resour. Manage. 8(1), 1-10.

Rasmussen, W.C., Andreasen, G.E., 1959. Hydrologic budget of the Beaverdam Creek Basin, Maryland. US Geol. Surv. Water Supply Pap. 1472, 106.

Rohde, M.M., Edmunds, W.M., Freyberg, D., Sharma, O.P. and Sharma, A., 2015. Estimating aquifer recharge in fractured hard rock: analysis of the methodological challenges and application to obtain a water balance (Jaisamand Lake Basin, India). Hydrogeol. J. 23(7): 1573-1586.

Selim, T., Bouksila, F., Berndtsson, R., Persson, M., 2013. Soil water and salinity distribution under different treatments of drip irrigation. Soil Sci. Soc. Am. J. 77(4), 1144-1156.

Sezen, S.M., Yazar, A. and Eker, S., 2006. Effect of drip irrigation regimes on yield and quality of field grown bell pepper. Agr. Water Manage. 81(1-2): 115-131.

Thanisawanyangkura, S., Sinoquet, H., Rivet, P., Cretenet, M. and Jallas, E., 1997. Leaf orientation and sunlit leaf area distribution in cotton. Agr. Forest Meteorol. 86(1-2): 1-15.

Valipour, M., 2012. Sprinkle and trickle irrigation system design using tapered pipes for pressure loss adjusting. J. Agr. Sci. 4(12):125-133.

Valipour, M., 2014a. Drainage, waterlogging, and salinity. Arch. Agron. Soil Sci. 60(12): 1625-1640.

Valipour, M., 2014b. Future of the area equipped for irrigation. Arch. Agron. Soil Sci. 60(12): 1641-1660.

Valipour, M., 2014c. Use of average data of 181 synoptic stations for estimation of reference crop 
evapotranspiration by temperature-based methods. Water Resour. Manage. 28(12): 4237-4255.

Valipour, M., Eslamian, S., 2014. Analysis of potential evapotranspiration using 11 modified temperature-based models. Int. J. Hydrol. Sci. Technol. 4(3): 192-207.

Valipour, M., 2015a. Future of agricultural water management in Africa. Arch. Agron. Soil Sci. 61(7): 907-927.

Valipour, M., 2015b. Comparative Evaluation of Radiation-Based Methods for Estimation of Potential Evapotranspiration. J. Hydrol. Eng. 20(5): 04014068.

Valipour, M., 2015c. Evaluation of radiation methods to study potential evapotranspiration of 31 provinces. Meteorol. Atmos. Phys. 127(3): 289-303.

Valipour, M., 2015d. Investigation of Valiantzas' evapotranspiration equation in Iran. Theor. Appl. Climatol. 121(1-2): 267-278.

Valipour, M., 2015e. Study of different climatic conditions to assess the role of solar radiation in reference crop evapotranspiration equations. Arch. Agron. Soil Sci. 61(5): 679-694.

Valipour, M., 2015f. Temperature analysis of reference evapotranspiration models. Meteorol. Appl. 22(3): 385-394.

Valipour, M., Ahmadi, M. Z., Raeini-Sarjaz, M., Sefidkouhi, M. A. G., Shahnazari, A., 2015. Agricultural water management in the world during past half century. Arch. Agron. Soil Sci. 61(5): 657-678.

Vazquez, N., Pardo, A., Suso, M.L., Quemada, M., 2006. Drainage and nitrate leaching under processing tomato growth with drip irrigation and plastic mulching. Agr. Ecosyst. Environ. 112(4), 313-323.

Wang, H., Zhang, L., Dawes, W. R., Liu, C., 2001. Improving water use efficiency of irrigated crops in 
the North China Plain -measurements and modeling, Agr. Water Manage. 48, 151-167.

Wang, H., Zhao, P., Cai, X., Wang, Q., Ma, L., Rao, X., Zeng, X., 2007. Partitioning of night sap flow of ACACIA MANGIUM and its implication for estimating whole-tree transpiration. J. Plant Ecol. 31(5), 777-786 (in Chinese with English abstract).

Wang, Q., Xu, Y., Wang, J., Wang, Y., Jiang, Q., 2002. Application of saline and slight saline water for farmland irrigation. Irrig. Drain. 21(4), 73-77 (in Chinese with English abstract).

Wang, Z., 2013. Study on the cotton-water-solute interactions under mulched drip irrigation with brackish water in an arid area. China University of Geosciences, Wuhan, China (in Chinese with English abstract).

Wang, Z., Jin, M., Šimůnek, J. and Al, E., 2014. Evaluation of mulched drip irrigation for cotton in arid Northwest China. Irrig. Sci. 32(1): 15-27.

Yang, J., Cheng, X., 2004. Rational exploitation and utilization of brackish water resource (in Chinese). China Water Resources News, Beijing, http://cds.chinawater.com.cn:8088/wasdemo/ detail?record=11\&channelid=113513\&searchword=bzqh\%3-D2025.

Zhang, Z.S., Zhang, X.Y., Tan, H.J., H,e M.Z., Zheng, J.G., Li, X.R., 2007a. Measurement on the transpiration of xerophils in the desert area with steady state porometer and stem heat balance technique. J. Beijing For. Univ. 29(1), 60-66 (in Chinese with English abstract).

Zhang, W.Q., He, K.N., Deng, J.T., Zhou, Y., Zhong, X.J., Li, Z.Q., 2007b. Comparison on the transpiration values measured with portable steady porometer method and whole-tree weighting method. Res. Soil Water Conservation, 14(6), 192-194 (in Chinese with English abstract).

Zhang, Z., Tian, F., Hu, H., Yang, P., 2014a. A comparison of methods for determining field evapotranspiration: photosynthesis system, sap flow, and eddy covariance. Hydrol. Earth Syst. Sc. 
18(3), 1053-1072.

Zhang, Z., Hu, H., Tian, F., Yao, X. and Sivapalan, M., 2014b. Groundwater dynamics under water-saving irrigation and implications for sustainable water management in an oasis: Tarim River basin of western China. Hydrol. Earth Syst. Sc., 18(10): 3951-3967. 


\section{Table Captions}

Table 1 Daily cotton transpiration and soil evaporation estimated by different methods at the experimental period in 2012 .

Table 2 Parameters of $\alpha$ and $1-\alpha$ are the ratios of sunlit and shaded leaf area to the total leaf area respectively, and $\beta$ is the ratio of transpiration rate of a shaded leaf to that of a sunlit leaf, at a specific time and canopy layer of the experimental site, modified from Zhang et al. (2014a).

Table 3 Soil water-and-salt budgets for the cotton field during the two irrigation periods of 14 August to 24 August, 2012. 


\section{Figure Captions}

Fig. 1 Location of the experimental site (Li, et al., 2015).

Fig. 2 Planting and drip-line arrangements in the cotton field, a the model of "one mulch, two drip lines and four rows", and $\mathbf{b}$ cotton field with a drainage channel (Li, et al., 2015).

Fig. 3 Irrigation events and groundwater table fluctuations during the experiment period of 14 August to 24 August in 2012 .

Fig. 4 Recharge estimated using the graphical approach to the WTF method with the hypothetical data (Delin, et al., 2007).

Fig. 5 Water level signal at SK3536 in December 2001 showing the Lisse effect (Crosbie R, et al., 2005).

Fig. 6 Leaf transpiration rate at measurement times of the experimental period. The solid circles are the mean value, and the error bars are the standard deviation.

Fig. 7 Leaf transpiration rate of different canopy layers at measurement times.

Fig. 8 Relationship between estimated $\left(M_{p}\right)$ and potential transpiration rate of measure times of the first two days after each of the two irrigation events during experimental period.

Fig. 9 Soil evaporation rate at measure times of the experimental period. The solid circles are the mean value, and the error bars are the standard deviation.

Fig. 10 Conceptual model of soil-water budget under mulched drip irrigation

Fig. 11 Distribution of a water content $(\theta) 2 \mathrm{~h}$ from an irrigation and $\mathbf{b}$ electric conductivity (EC) immediately after the irrigation on 20 August 2012 (Li, et al., 2015).

Fig. S1 The regional relief map 

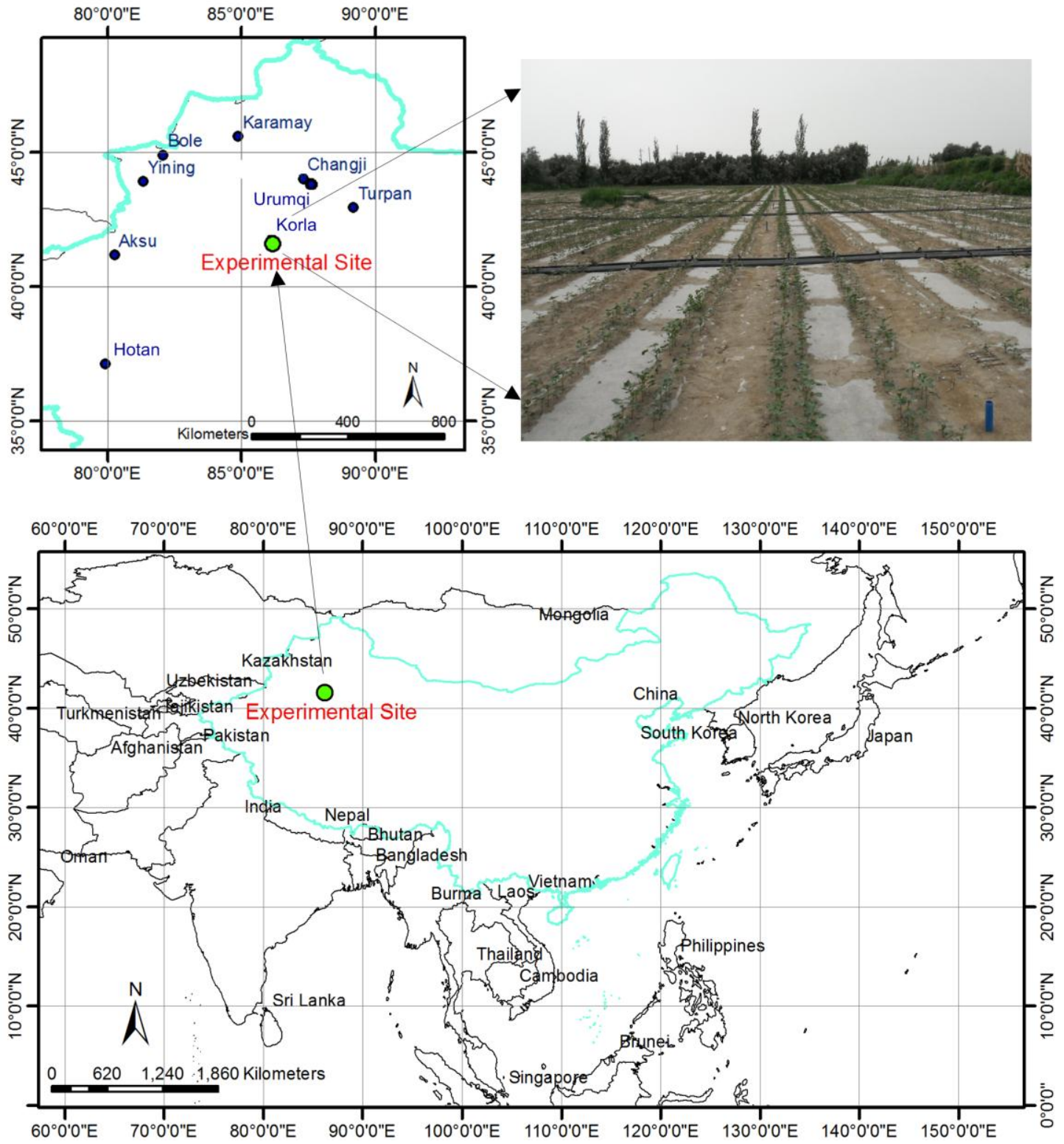


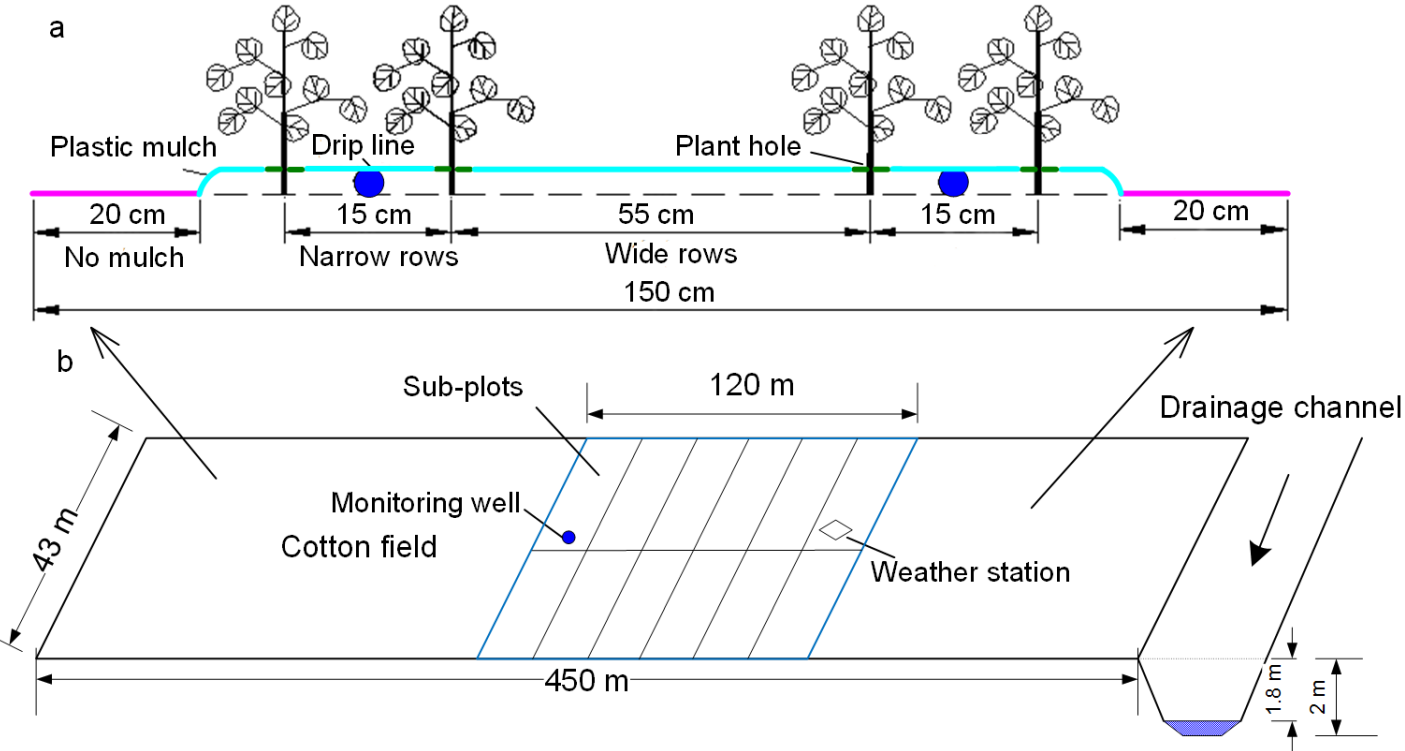




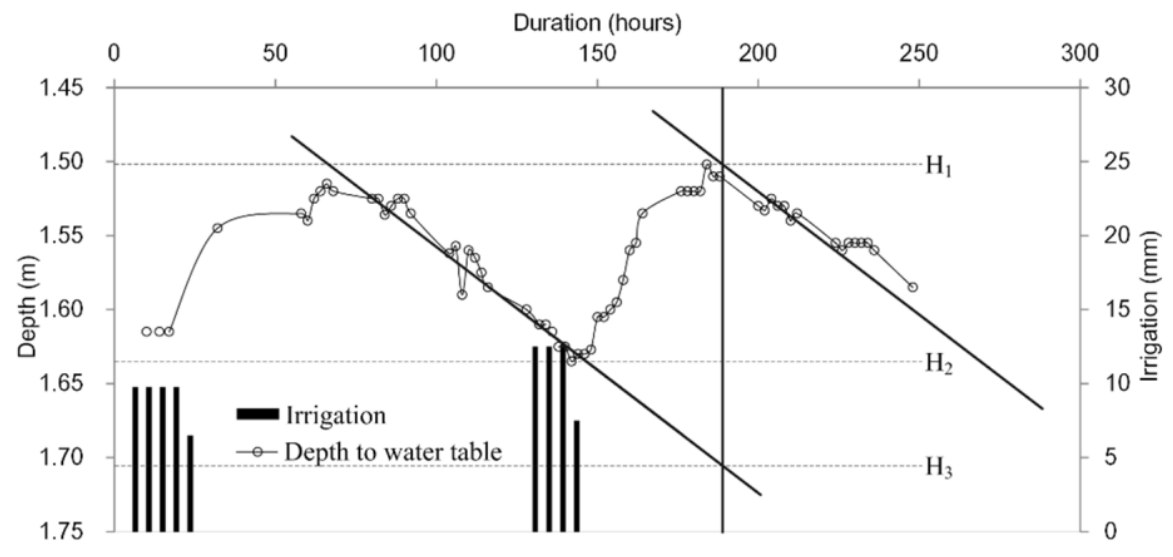




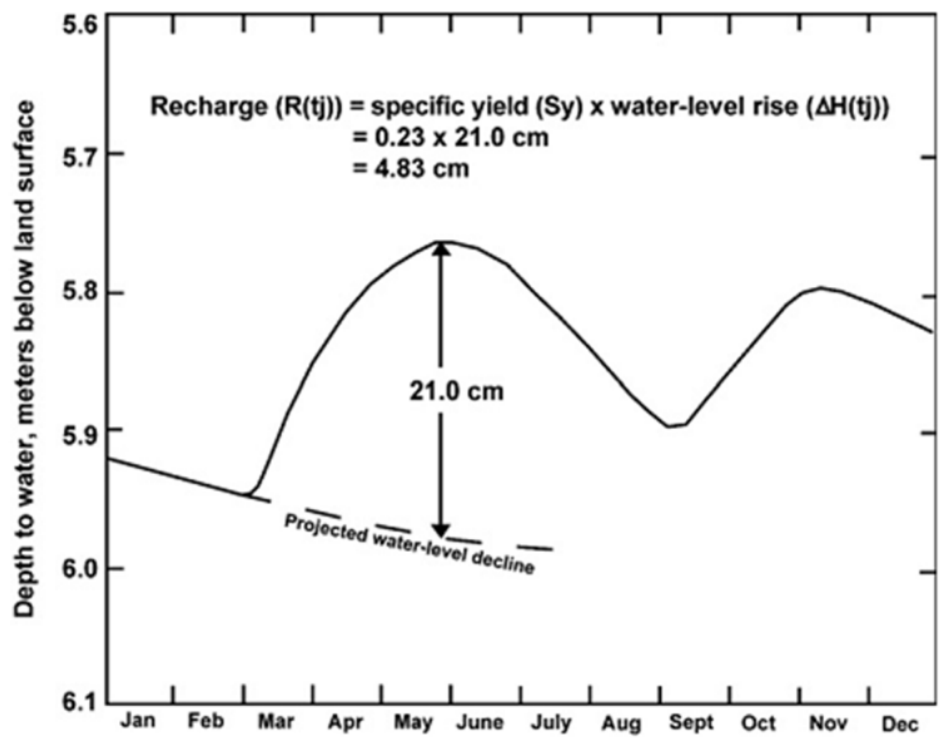




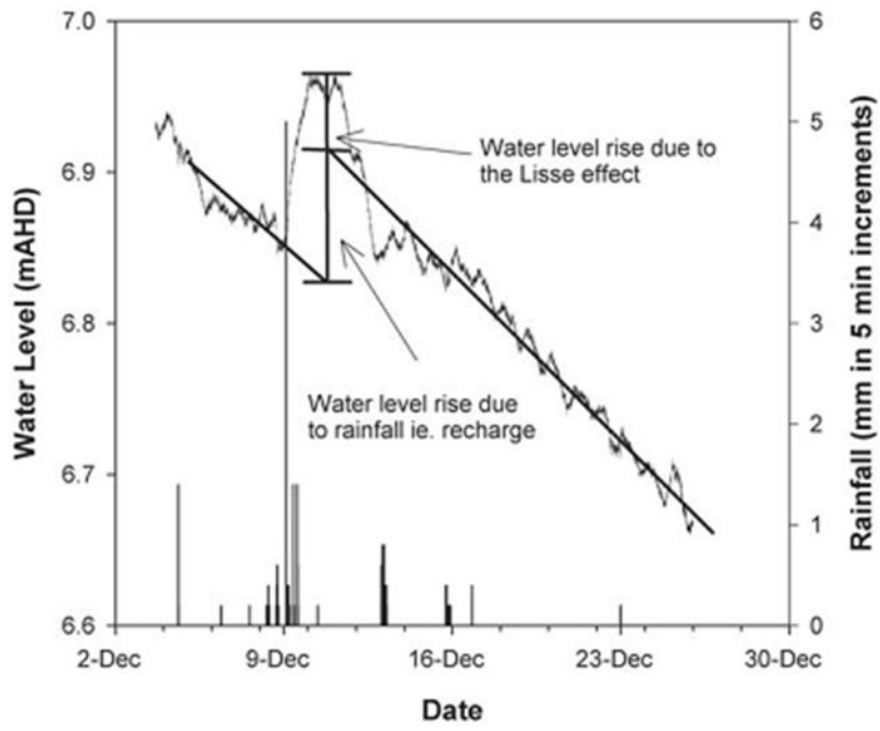




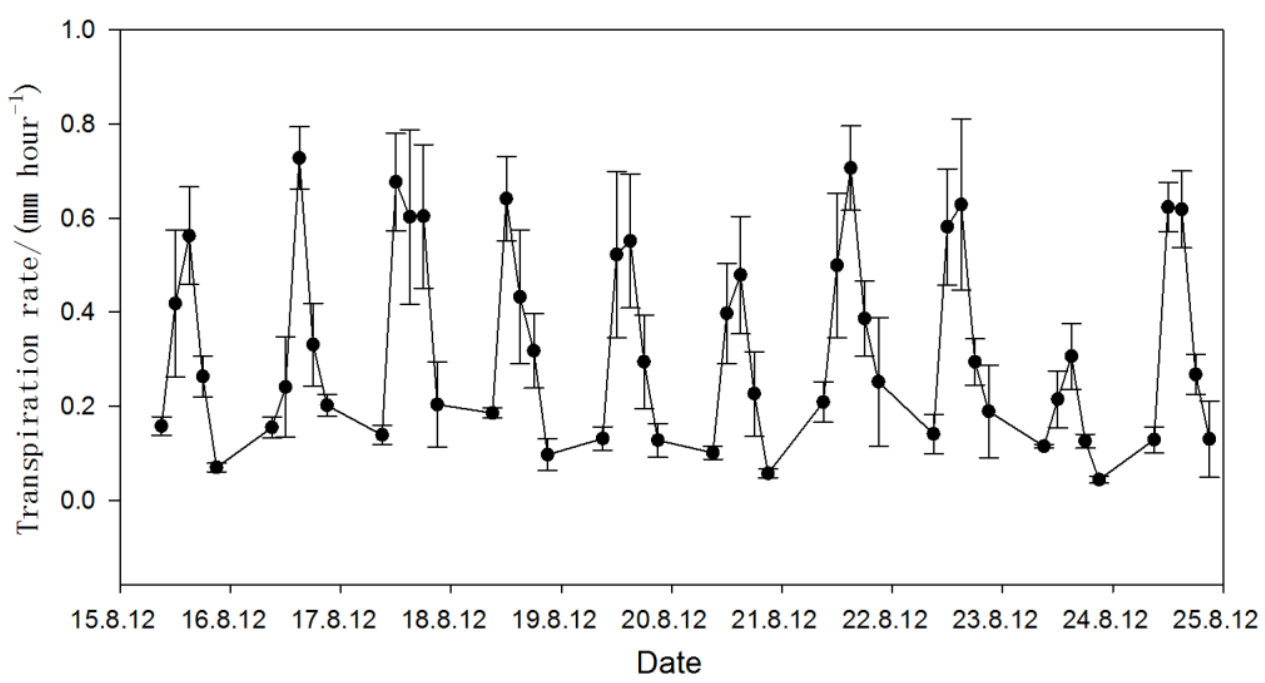




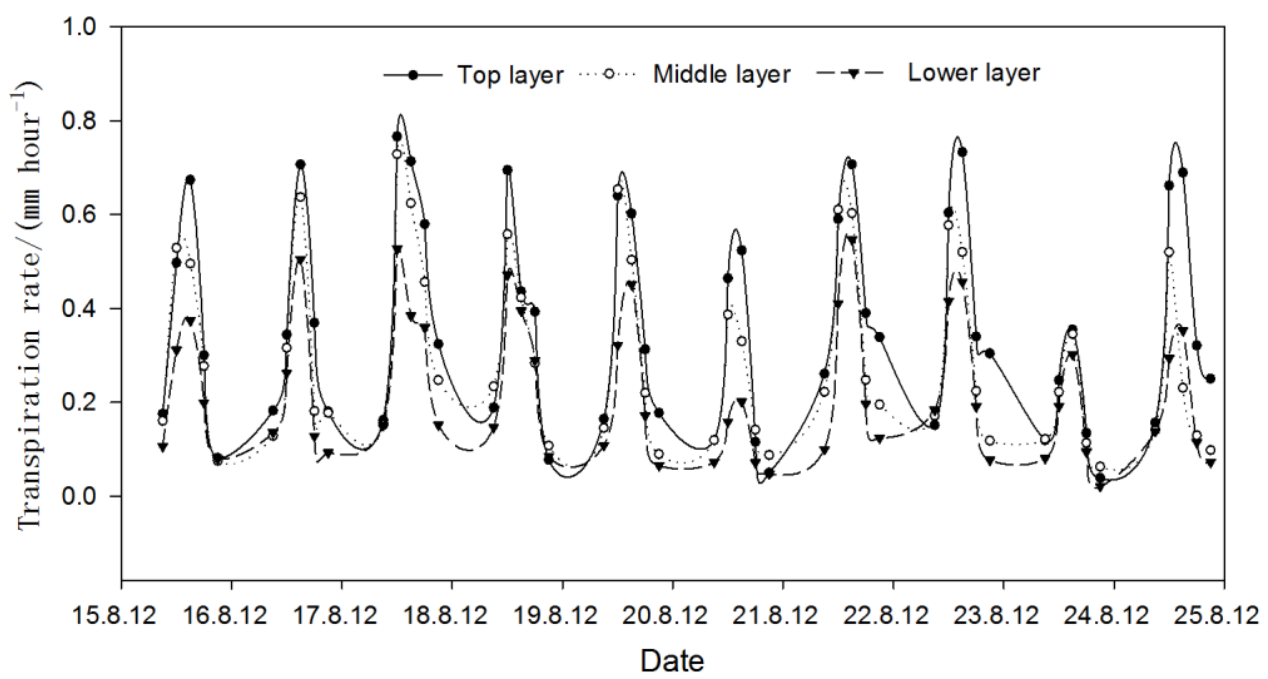




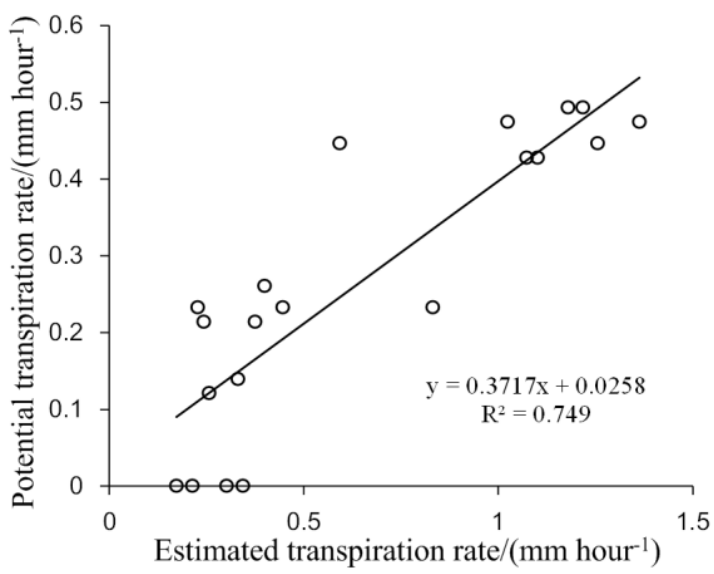




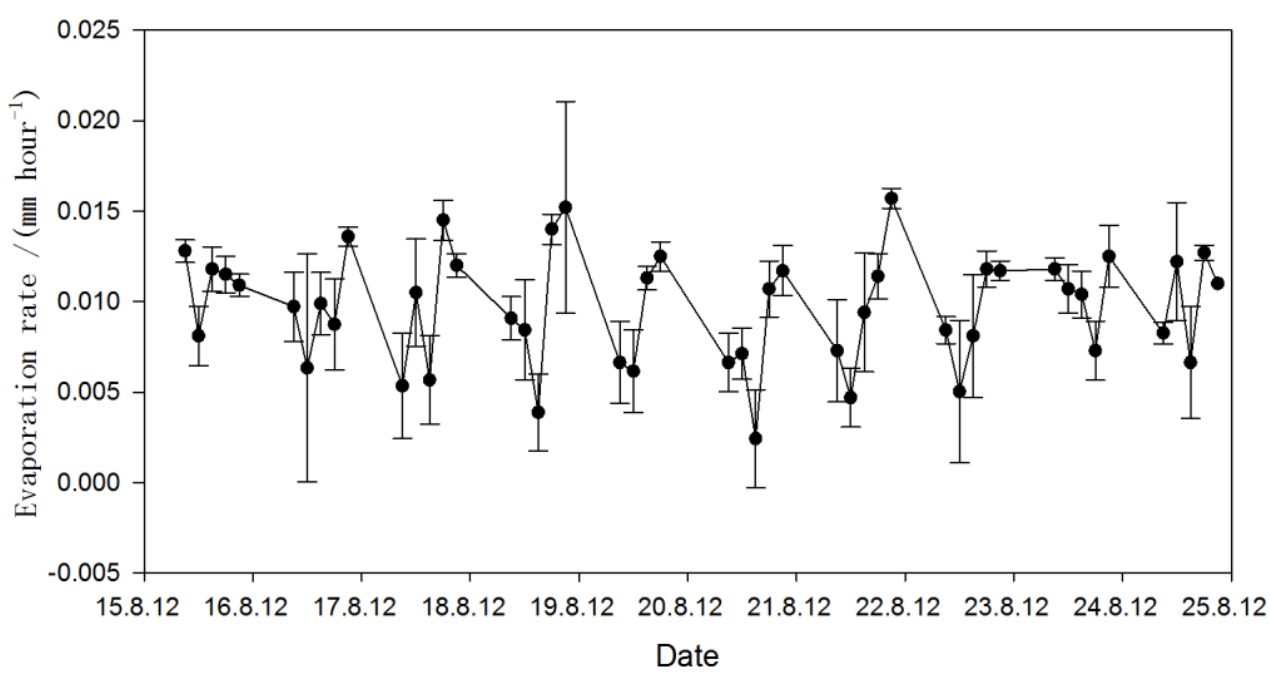




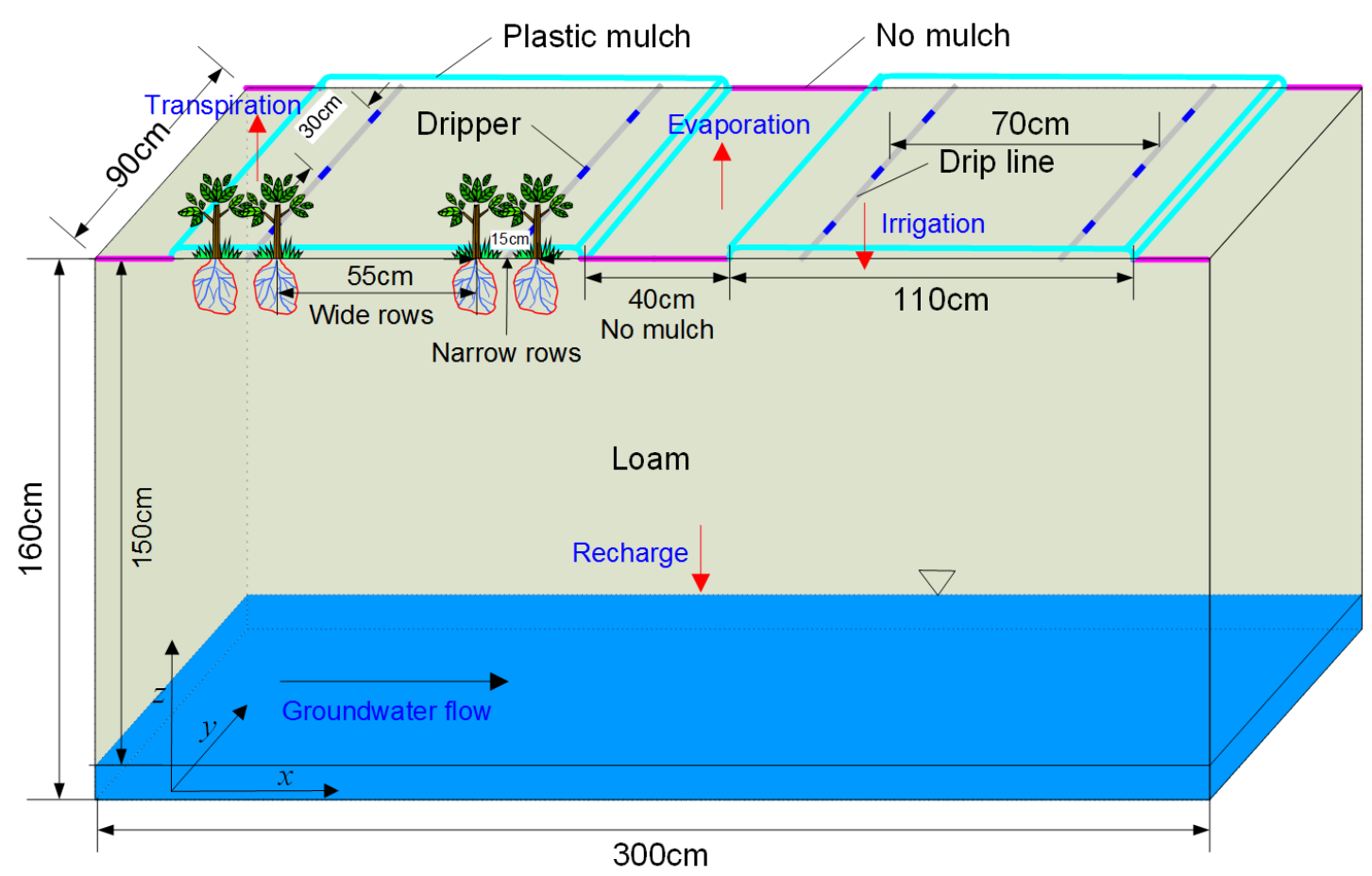



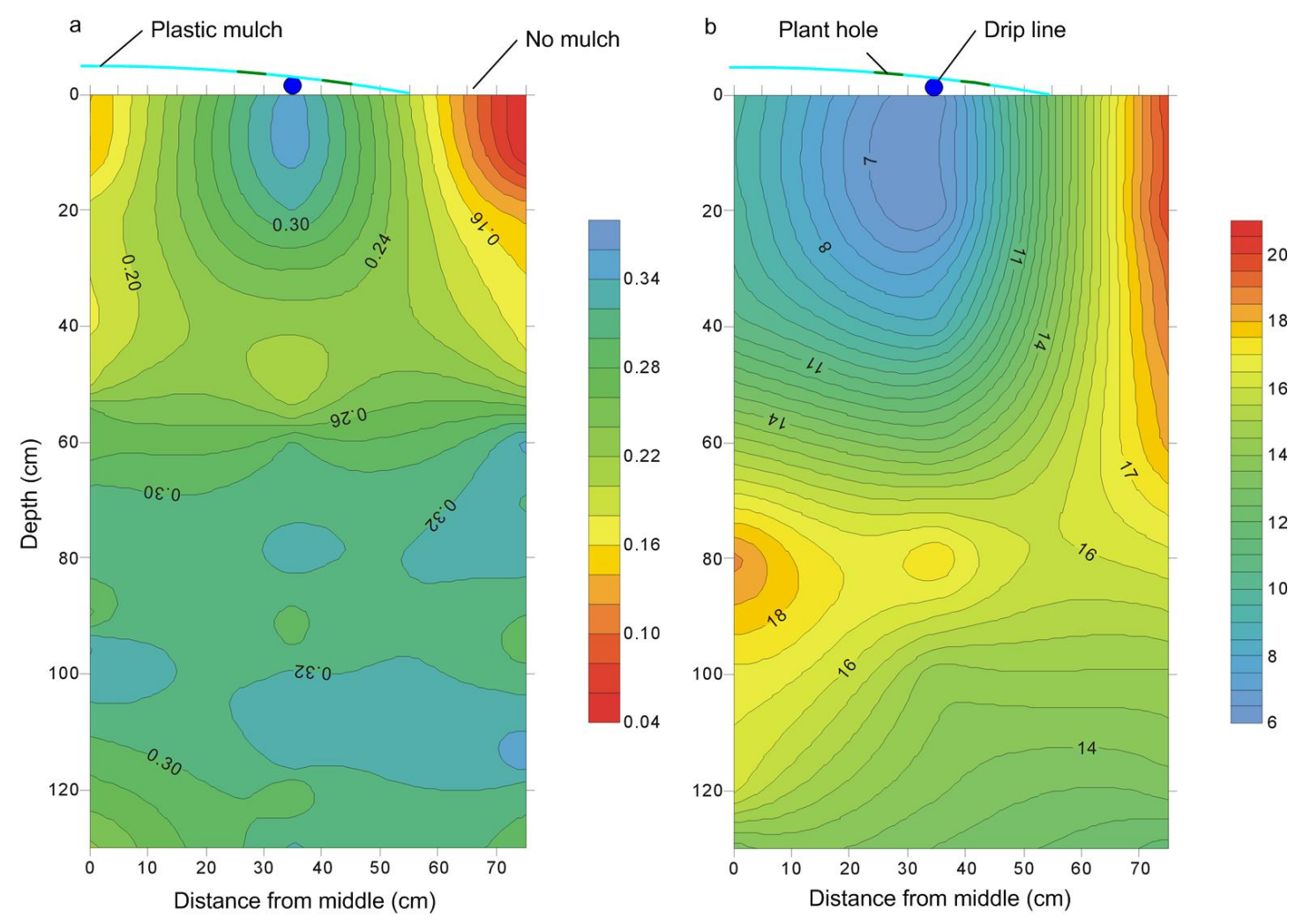
Table 1 Daily cotton transpiration and soil evaporation estimated by different methods at the experimental period in 2012 Unit: $\mathrm{mm}$

\begin{tabular}{llllllllllllll}
\hline & 15 & 16 & 17 & 18 & 19 & 20 & 21 & 22 & 23 & 24 & Total \\
Date & & & & & & & & & & & \\
& Aug. & Aug. & Aug. & Aug. & Aug. & Aug. & Aug. & Aug. & Aug. & Aug. & $(0.0)$ \\
\hline$T_{p}$ & 3.26 & 5.05 & 5.02 & 4.12 & 4.97 & 4.83 & 4.35 & 4.0 & $\mathbf{2 . 7 2}$ & 4.96 & 43.3 \\
& & & & & & & & & & & \\
$T_{\text {SRS-2000 }}$ & 6.81 & 6.69 & 9.81 & 7.53 & 7.29 & 4.41 & 8.39 & 7.41 & $\mathbf{3 . 8 1}$ & 6.45 & 68.6 \\
& & & & & & & & & & & \\
$\boldsymbol{T}_{\mathbf{c}}$ & $\mathbf{3 . 0 9}$ & $\mathbf{2 . 9 7}$ & $\mathbf{4 . 1 7}$ & $\mathbf{3 . 3 3}$ & $\mathbf{3 . 2 1}$ & $\mathbf{2 . 1 3}$ & $\mathbf{3 . 6 9}$ & $\mathbf{3 . 2 1}$ & $\mathbf{2 . 0 1}$ & $\mathbf{2 . 8 5}$ & $\mathbf{3 0 . 7}$ \\
& & & & & & & & & & & \\
$E_{T_{0}-T_{\mathrm{p}}}$ & 0.24 & 0.38 & 0.38 & 0.31 & 0.37 & 0.36 & 0.33 & 0.30 & 0.20 & 0.37 & 3.2 \\
& & & & & & & & & & & \\
$\boldsymbol{E}_{\text {SRS-2000 }}$ & $\mathbf{0 . 0 4 3}$ & $\mathbf{0 . 0 4 5}$ & $\mathbf{0 . 0 4 8}$ & $\mathbf{0 . 0 3 7}$ & $\mathbf{0 . 0 4 3}$ & $\mathbf{0 . 0 4 0}$ & $\mathbf{0 . 0 4 3}$ & $\mathbf{0 . 0 3 4}$ & $\mathbf{0 . 0 4 5}$ & $\mathbf{0 . 0 5 1}$ & $\mathbf{0 . 4}$ \\
\hline
\end{tabular}

Note: $T_{\mathrm{c}}$ is the actual cotton transpiration estimated by conversion method. 
Table 2 Parameters of $\alpha$ and $1-\alpha$ are the ratios of sunlit and shaded leaf area to the total leaf area respectively, and $\beta$ is the ratio of transpiration rate of a shaded leaf to that of a sunlit leaf, at a specific time and canopy layer of the experimental site, modified from Zhang et al. ( 2014).

\begin{tabular}{|c|c|c|c|c|c|c|c|c|c|}
\hline \multirow{4}{*}{ Time } & \multicolumn{3}{|c|}{ Top layer } & \multicolumn{3}{|c|}{ Middle layer } & \multicolumn{3}{|c|}{ Lower layer } \\
\hline & \multicolumn{3}{|c|}{$10.1 \%$ of the leaf area of a } & \multicolumn{3}{|c|}{$60.5 \%$ of the leaf area of a } & \multicolumn{3}{|c|}{$29.4 \%$ of the leaf area of a } \\
\hline & \multicolumn{3}{|c|}{ plant } & \multicolumn{3}{|c|}{ plant } & \multicolumn{3}{|c|}{ plant } \\
\hline & $\alpha$ & $1-\alpha$ & $\beta$ & $\alpha$ & $1-\alpha$ & $\beta$ & $\alpha$ & $1-\alpha$ & $\beta$ \\
\hline 9:00 & 0.29 & 0.71 & 0.55 & 0.21 & 0.79 & 0.44 & 0.17 & 0.83 & 0.26 \\
\hline $12: 00$ & 0.33 & 0.67 & 0.64 & 0.23 & 0.77 & 0.54 & 0.20 & 0.80 & 0.46 \\
\hline $15: 00$ & 0.34 & 0.66 & 0.58 & 0.24 & 0.76 & 0.45 & 0.21 & 0.79 & 0.65 \\
\hline 18:00 & 0.29 & 0.71 & 0.39 & 0.21 & 0.79 & 0.46 & 0.17 & 0.83 & 0.34 \\
\hline 21:00 & 0.14 & 0.86 & 0.47 & 0.17 & 0.83 & 0.40 & 0.12 & 0.88 & 0.40 \\
\hline
\end{tabular}

Note: Time in the table is Beijing time. 
Table 3 Soil water-and-salt budgets for the cotton field during the two irrigation periods of 14 August to 24 August, 2012

\begin{tabular}{|c|c|c|c|c|c|c|}
\hline Budget & \multicolumn{2}{|c|}{ Input items } & \multicolumn{3}{|c|}{ Output items } & variation \\
\hline \multirow{4}{*}{$\begin{array}{l}\text { Soil-water } \\
\text { budget }(\mathrm{mm})\end{array}$} & \multicolumn{2}{|c|}{ Irrigation $(I)$} & Recharge to & Evaporation & Transpiration & Variation of \\
\hline & & & groundwater & $(E)$ & $(T)$ & water storage \\
\hline & & & $\left(R_{\mathrm{g}}\right)$ & & & $(\Delta W)$ \\
\hline & \multicolumn{2}{|c|}{90.6} & 48.2 & 0.4 & 30.7 & 11.3 \\
\hline & Salt form & Salt form & \multicolumn{3}{|c|}{ Salt with recharge to groundwater $\left(R_{g} C_{g}\right)$} & Variation of salt \\
\hline & irrigation & fertilizer & & & & storage $(\Delta S)$ \\
\hline & $\left(I C_{i}\right)$ & $\left(S_{f}\right)$ & & & & \\
\hline & 217 & 10 & & 342 & & -115 \\
\hline
\end{tabular}

